\title{
Flexural behaviour of hybrid laminated composites
}

\author{
P.N.B. Reis ${ }^{\text {a }}$, J.A.M. Ferreira ${ }^{\text {b,* }}$, F.V. Antunes ${ }^{\text {b }}$, J.D.M. Costa ${ }^{b}$ \\ ${ }^{a}$ Department of Electromechanical Engineering, UBI - University of Beira Interior, 6200 Covilhã, Portugal \\ ${ }^{\mathrm{b}}$ Department of Mechanical Engineering, FCTUC - University of Coimbra, Polo II, 3030 Coimbra, Portugal
}

Received 16 February 2006; received in revised form 23 October 2006; accepted 29 November 2006

\begin{abstract}
The present paper studies the flexural behaviour of hand manufactured hybrid laminated composites with a hemp natural fibre/polypropylene core and two glass fibres/polypropylene surface layers at each side of the specimen. When compared with full glass fibres reinforced polypropylene laminates, the hybrid composites have economical, ecological and recycling advantages and also specific fatigue strength benefits. Static and fatigue tests were performed in three point bending for both laminates to evaluate flexural strength properties and fatigue behaviour. Fatigue damage was measured in terms of the stiffness loss. Failure sites and mechanisms were evaluated through microscopy studies and a 3D numerical analysis using finite element method.
\end{abstract}

(C) 2006 Elsevier Ltd. All rights reserved.

Keywords: A. Hybrid; B. Fatigue; C. Damage mechanisms; C. Finite element analysis

\section{Introduction}

Composite laminates offer alternative material design solutions in terms of specific strength and stiffness allowing important weight savings. They also offer significant freedom to the designer by allowing, optimizing the strength and stiffness of a component or structure for a particular application. Furthermore, thermoplastic resins present increased interest due to their economic and mechanical advantages, such as easy fabrication, unlimited shelf life, intrinsic recyclability, high toughness and increased moisture resistance [1].

Recently an increasing use of composites reinforced with natural fibres $[2,3]$ has occurred, owing the following advantages: they are strong enough, light in weight, abundant, non-abrasive and cheap [3-5]. The vegetable fibres are renewable and biodegradable and are available throughout the world. Concerning their intrinsic properties, this type of fibres presents a specific weight that is about half of the weight of glass fibres and a tensile mod-

\footnotetext{
${ }^{*}$ Corresponding author. Tel.: +351 239790700; fax: +351 239790701.

E-mail address: martins.ferreira@dem.uc.pt (J.A.M. Ferreira).
}

ulus quite similar to aramid fibres [2]. However, the mechanical properties of these fibres are dependent on the cellulose content in the fibre, the degree of polymerisation of the cellulose and the microfibril angle [6]. Fibres with higher cellulose content, higher degree of polymerisation and a lower microfibrillar angle exhibit higher tensile strength and modulus [6].

Kline's study [7] reported an annual growth rate for natural fibre composites about $60 \%$ over the years 2000-2005. The major part of this growth was observed in building applications [6], where the wood fibre composites present a wide applicability. The automotive industry is also including some components in natural fibres reinforced thermoplastics as a way to serve the environment along with weight and cost savings. Applications of natural fibres in automotive applications have been limited to interior components and truck cabins $[6,8]$ to replace the components previously made with glass fibre composites $[9,10]$.

The hemp fibres were the world's largest agricultural crop in the early 19th century, but the interest in this material has declined with advances in the field of the synthetic fibres. Actually, the interest is returning due to the global environmental issues. These fibres have a strong 
Table 1

Comparative values of physical and mechanical properties of hemp with E-glass fibre [12-15]

\begin{tabular}{lllll}
\hline Fibre & Density $\left(\mathrm{g} / \mathrm{cm}^{3}\right)$ & Elongation to break $(\%)$ & Tensile strength $(\mathrm{MPa})$ & Young's modulus $(\mathrm{GPa})$ \\
\hline Hemp & $1.14-1.48$ & $1.6-1.8$ & $550-900$ & $30-70$ \\
E-glass & $2.5-2.6$ & $2.5-3.2$ & $2000-3500$ & $70-73$ \\
\hline
\end{tabular}

applicability, for example, in the automotive industry in components like interior door trim panels, engine shields, gaskets, seat parts, etc. Bledzki et al. [11] presents the typical chemical composition and structure of hemp fibres. The values for the mechanical and physical properties of the hemp and the E-glass fibre, for comparison, are presented in Table 1 [12-15]. According to Van de Velde and Kiekens [13] the fibre properties are influenced by many factors such as: cultivation (variety, climate, harvest, maturity, retting degree), processing (decortication, disintegration) and fibre modification (textile and technical processes).

The lower thermal stability of natural fibres, limits the thermoplastics, whose processing temperature is below $230{ }^{\circ} \mathrm{C}$, to be used as matrix [5]. These are, most of all, polyolefines, such as polyethylene and polypropylene [16]. In particular, the polypropylene offers several favorable characteristics like low price, high toughness, low density, relatively high thermal stability, good (di)electrical properties, chemical resistance, easy processing and recycling ability $[6,13,16,17]$.

Another area of concern relates to the poor moisture resistance and dimensional stability of natural fibres, which can lead to debonding and microcracking in the composite. On the other hand, all polymer composites absorb moisture in humid atmosphere and when immersed in water. The effect of absorption of moisture leads to the degradation of fibre-matrix interface region creating poor stress transfer efficiencies resulting in a reduction of mechanical and dimensional properties. In this case, being hydrophilic, natural fibres need to be treated first to make them more compatible with hydrophobic thermosets and thermoplastics. It has been reported by several authors that modification of fibres improved the mechanical properties of the composites [18-23] and the sensitivity of certain mechanical and thermal properties to moisture uptake can be reduced [15,24,25]. Mwaikambo and Ansell [23], for example, treated hemp, jute, sisal and kapok fibres with various concentrations of $\mathrm{NaOH}$ and found $6 \%$ to be the optimized concentration in terms of cleaning the fibre bundle surfaces yet retaining a high index of crystallinity.

The development of hybrid composites is motivated by the ability to combine advantageous features of various fibre systems, improving performance and flexibility, as well as reducing weight and cost. The understanding how the mechanical properties of hybrid composites depend on the constituents have an evident importance for the designers. It is possible to find in the literature several studies for fatigue behaviour of hybrid composites [26-29].
The objective of this paper was to study the static and fatigue flexural strength of hybrid laminates fabricated with natural fibre/polypropylene core and glass fibres reinforced polypropylene skins. It is expected that they can offer an equivalent specific stiffness and strength when compared with full glass fibre reinforced polypropylene laminates but with economical, ecological and recycling advantages. The static and fatigue properties of full glass fibres laminates were analyzed in previous works of the authors $[30,31]$ for tensile loadings. However, flexural strength of the laminates is not only influenced by tensile stresses but also by shear stresses and, therefore, the interlaminar fracture toughness of the interface layers plays an important role.

\section{Materials, experimental and numerical procedure}

Laminated composites (LC) sheets formed from multiple layers of Vertotex "Twintex TPP" were processed in a mould under a pressure of 5 bar during $10 \mathrm{~min}$, after heating at $190{ }^{\circ} \mathrm{C}$ (temperature above the melting temperature of the polypropylene). For each sheet seven woven balanced bidirectional layers were used, all in the same orientation as shown in Fig. 1a. Twintex TPP is a woven mat of polypropylene (PP) reinforced with glass fibres type E containing a fibre volume fraction $33.4 \%$. The hybrid laminated composites (HLC) were manufactured in the same conditions, with the following layer sequence: TPP/ $\mathrm{TPP} / \mathrm{PP} / \mathrm{H} / \mathrm{PP} / \mathrm{H} / \mathrm{PP} / \mathrm{TPP} / \mathrm{TPP}$ as depicted in Fig. 1b. In this case, PP represents a layer of Polypropylene, TPP are layers of Vertotex material and $\mathrm{H}$ is another layer with long hemp fibres hand randomly distributed. Non-woven
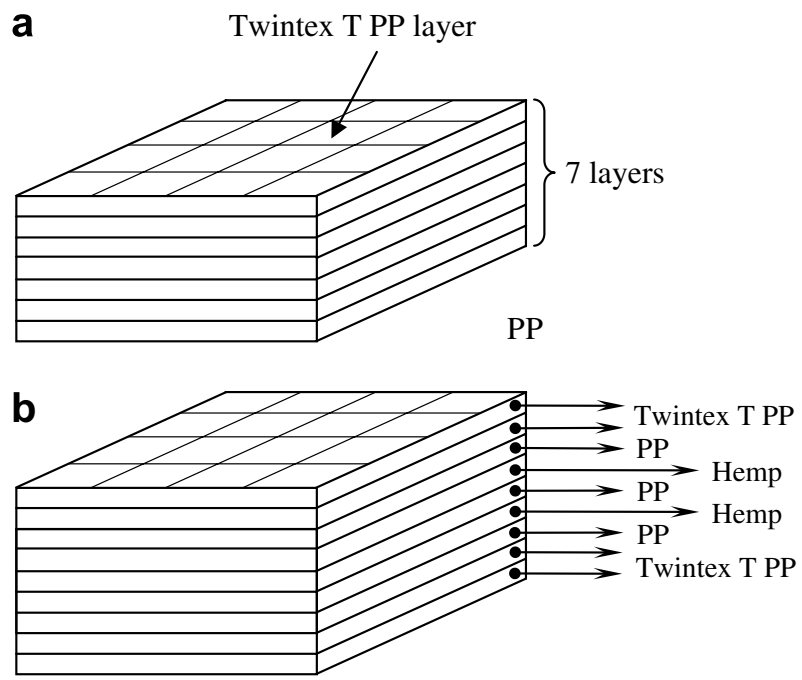

Fig. 1. Schematic view of the cross-sections of LC and HLC materials. 

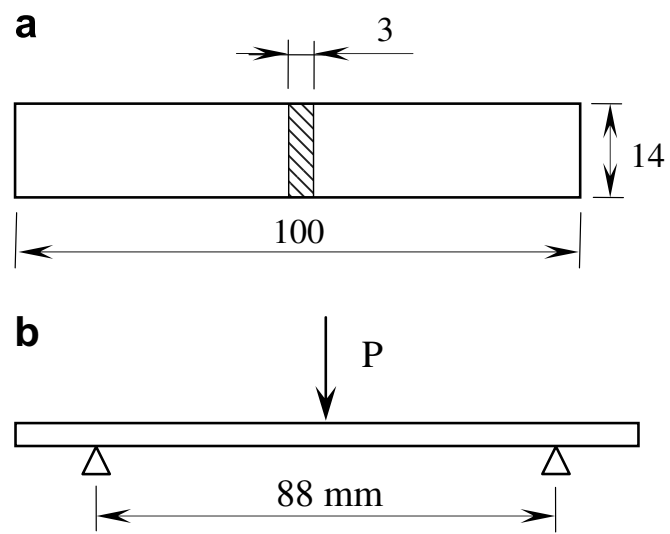

Fig. 2. (a) Specimens geometry (dimensions in $\mathrm{mm}$ ); (b) schematic view of the three point bending apparatus.

hemp fibre mat was first dried at $100{ }^{\circ} \mathrm{C}$ to remove storage moisture in a fan-assisted oven. The desired amount of preweighed hemp fibre was hand uniformly distributed and placed in the mould. The predicted fibre volume fraction of the core was $12 \%$. The overall nominal dimensions of the mould were $250 \times 60 \times 3 \mathrm{~mm}$. The mean measured thickness of the manufactured sheets was $3.08 \mathrm{~mm}$ with standard deviation of $1.67 \%$ for LC specimens and $3.24 \mathrm{~mm}$ with standard deviation of $5.76 \%$ for the HLC specimens. Quality control was done by visual inspection of both colour and void content.
The specimens used in the static and fatigue three point bending tests, were cut from these plates, being the bending stresses oriented with one fibre direction of the skins. Fig. 2a shows the dimensions of the specimens while Fig. $2 b$ shows a schematic view of the three point bending apparatus.

The static tests were performed in an electromechanical Zwick, model 1435, with a displacement rate of $5 \mathrm{~mm} / \mathrm{s}$ according the recommendations of ASTM D 2344 Standard [32]. Four specimens were tested for each material (LC and HLC). The fatigue tests were carried out at room temperature in an electromechanical machine where the frequency and stress ratio can be changed. A load cell was used to monitor the load. The load wave was sinusoidal with constant amplitude, having a stress ratio of $R=0.25$ and a frequency of $10 \mathrm{~Hz}$.

The nominal bending stress $(\sigma)$ was calculated using:

$\sigma=\frac{3 P L}{2 b h^{2}}$

being $P$ the load, $L$ the span length, $b$ the width and $h$ the thickness of the specimen.

A 3D numerical analysis was performed, considering only $1 / 4$ of the specimen along with adequate boundary conditions. The physical model considered in the numerical analysis is presented in Fig. 3. The model was loaded with $50 \mathrm{~N}$ as indicated, for a total specimen load of $200 \mathrm{~N}$.

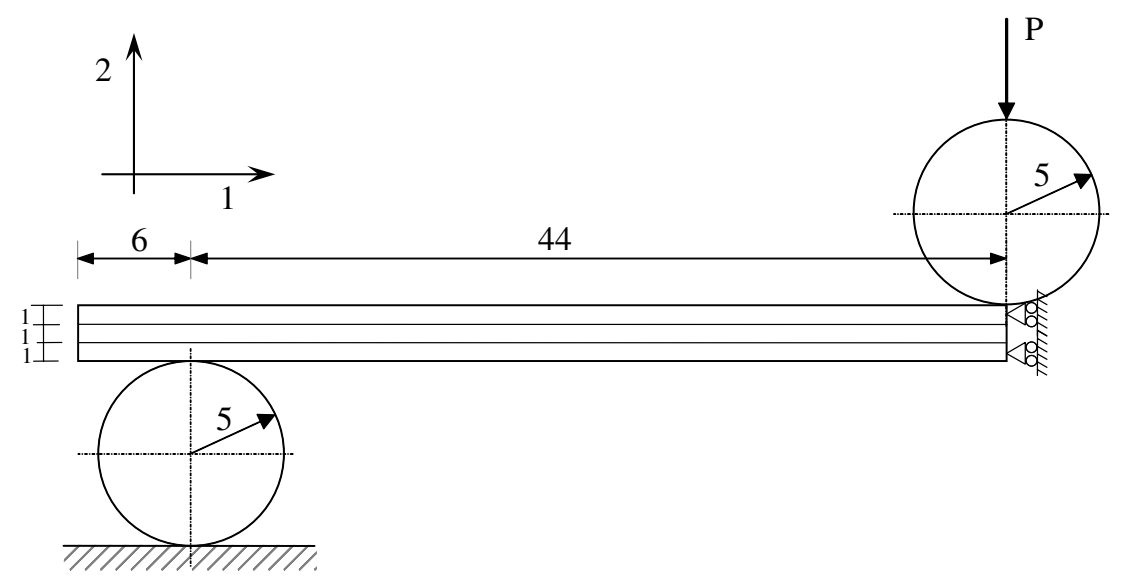

Fig. 3. Physical model of three-point bend geometry (dimensions in $\mathrm{mm}$ ).

Table 2

Orthotropic elastic properties

\begin{tabular}{llll}
\hline Property & Twintex & PP + natural fibres & Comment \\
\hline$E_{1}(\mathrm{MPa})$ & 17,300 & 3370 & Experimental value \\
$E_{2}(\mathrm{MPa})$ & 1500 & 1500 & Typical value for PP \\
$E_{3}(\mathrm{MPa})$ & 17,300 & 3370 & $=E_{1}$ \\
$v_{12}[-]$ & 0.32 & 0.32 & Typical value for PP \\
$v_{23}[-]$ & 0.028 & 0.142 & Considering orthotropic properties \\
$v_{31}[-]$ & 0.125 & 0.39 & Experimental value \\
$\mathrm{G}_{12}(\mathrm{GPa})$ & 65.5 & 1.28 & $=E_{1} /\left[2\left(1+v_{12}\right)\right]$ \\
$\mathrm{G}_{23}(\mathrm{GPa})$ & 0.73 & 0.66 & $=E_{2} /\left[2\left(1+v_{23}\right)\right]$ \\
$\mathrm{G}_{31}(\mathrm{GPa})$ & 7.68 & 1.21 & $=E_{3} /\left[2\left(1+v_{31}\right)\right]$ \\
\hline
\end{tabular}



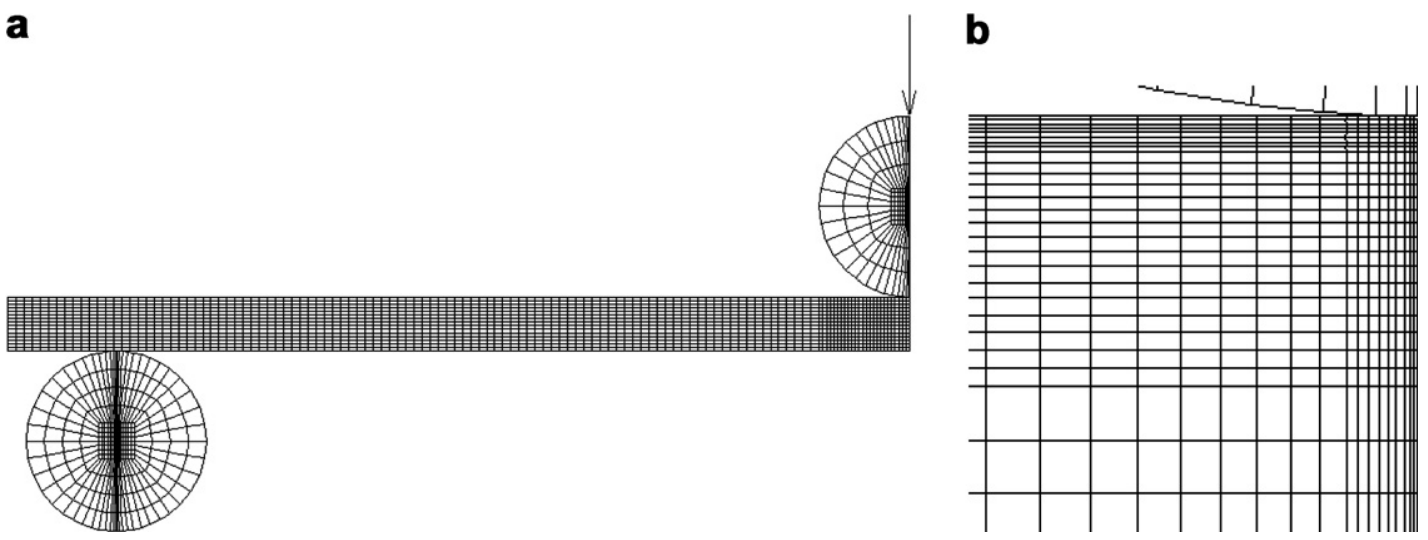

Fig. 4. (a) Finite element mesh. (b) Mesh detail near contact region.

For hybrid laminated composites (HLC) three different material layers were considered, each having a thickness of $1 \mathrm{~mm}$. The inside layer was made of PP reinforced with natural fibres and the other two were made of Twintex TPP composite. On the other hand, for the laminated composite (LC) sheets, only a $3 \mathrm{~mm}$ thick layer of Twintex TPP was considered. The materials were assumed to be continuous, homogeneous and with orthotropic linear elastic behaviour. All the orthotropic properties that are essential for this study are presented in Table 2 . The main orthotropic directions are coincident with Cartesian coordinate system indicated in Fig. 3.

The physical model was analyzed by the finite element method using commercial finite element package MARCMENTAT 2003 [33]. Linear isoparametric elements with full integration were considered. Fig. 4 presents a finite element mesh having a total number of 27320 elements and 32509 nodes.

\section{Results and discussion}

The flexural properties of the laminated and hybrid laminated composites were obtained by 3PB static tests. Typical load-displacement curves for both materials are plotted in Fig. 5. Both materials show a nearly fragile behaviour with a non-linear region only at the end of the tests and a sudden drop of the stress after peak stress was reached. The zigzag aspect of the load-displacement curve, for LC laminates, denotes a more stable propagation regime than the one observed for hybrid composites. This behaviour indicates the existence of different damage mechanisms.

Table 3 presents the results obtained in 3PB static tests, the average values and the standard deviation. The laminate composites (LC) present an ultimate strength about $4 \%$ higher than the hybrid composites (HLC), while the Young's modulus was about $3.8 \%$ higher. The variation of bending strength is associated with the changes in failure mechanisms. Specific mass of LC and HLC laminates was obtained using the Archimedes principle. The values obtained were $1.48 \mathrm{~g} / \mathrm{cm}^{3}$ and $1.16 \mathrm{~g} / \mathrm{cm}^{3}$ for LC and HLC composites, respectively. Considering these values,

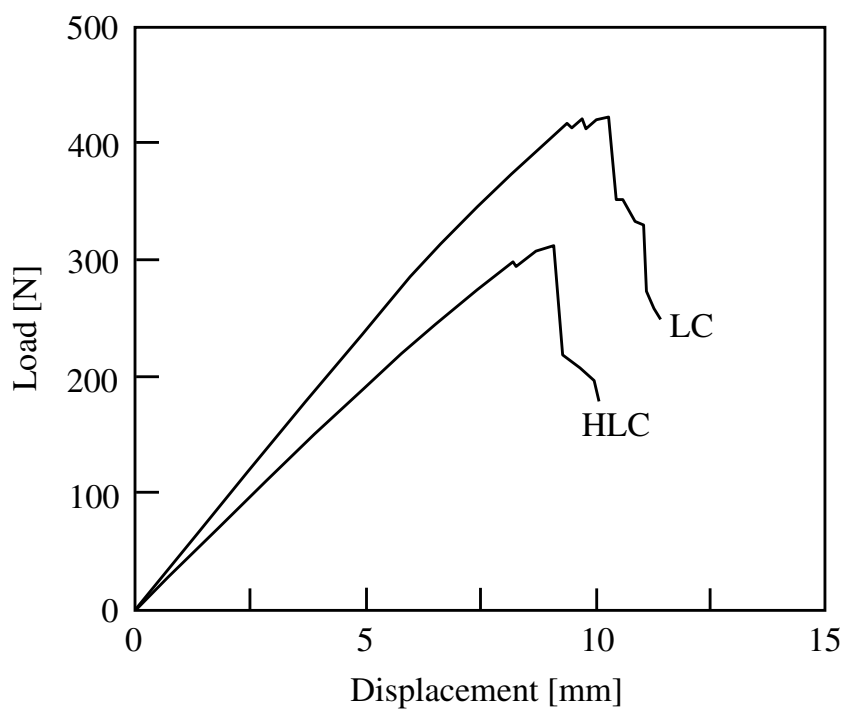

Fig. 5. Load-displacement curves for laminate and hybrid composites.

the specific flexural strength and flexural stiffness are around $22 \%$ higher in HLC composites than in LC laminates.

Typical pictures of the different failure mechanisms observed for laminated and hybrid laminated composites are presented in Fig. 6a and b, respectively. For laminated composites the picture shows the main damage process, composed of fibres fracture in the compressive surface followed by delaminations between the TPP layers. Probably, the zigzag aspect of the curves showed in Fig. 5 results from several sequential fibre breakage events. The drop of the ultimate load is a consequence of the long delaminations and catastrophic broken fibres. For all specimens tested the fibres submitted to tensile stresses did not break and the main failure process occurs in compression.

The failure process for the hybrid laminated composites is faster in spite of the similarity with the laminate composites. The ruptures of the fibres appear first in compression region, like in the laminated composites, followed by a long delamination between the surface layers, as a consequence of the high gradients of shear and normal stresses. In this case the rupture of the fibres also occurs in tension region. 
Table 3

Three points bending properties

\begin{tabular}{|c|c|c|c|c|c|c|}
\hline & $\sigma_{\mathrm{UTS}}(\mathrm{MPa})$ & $\begin{array}{l}\text { Average } \sigma_{\mathrm{UTS}} \\
(\mathrm{MPa})\end{array}$ & $\begin{array}{l}\text { Standard deviation } \\
(\mathrm{MPa})\end{array}$ & $E(\mathrm{GPa})$ & Average $(\mathrm{GPa})$ & $\begin{array}{l}\text { Standard deviation } \\
(\mathrm{GPa})\end{array}$ \\
\hline Laminated composite & $\begin{array}{l}352 \\
462 \\
351 \\
359\end{array}$ & 381 & 54 & $\begin{array}{l}11.4 \\
11.2 \\
13.2 \\
11.2\end{array}$ & 11.8 & 0.97 \\
\hline $\begin{array}{l}\text { Hybrid laminated } \\
\text { composite }\end{array}$ & $\begin{array}{l}313 \\
363 \\
403 \\
385\end{array}$ & 366 & 39 & $\begin{array}{l}10.9 \\
11.7 \\
11.4 \\
11.2\end{array}$ & 11.3 & 0.34 \\
\hline
\end{tabular}

a

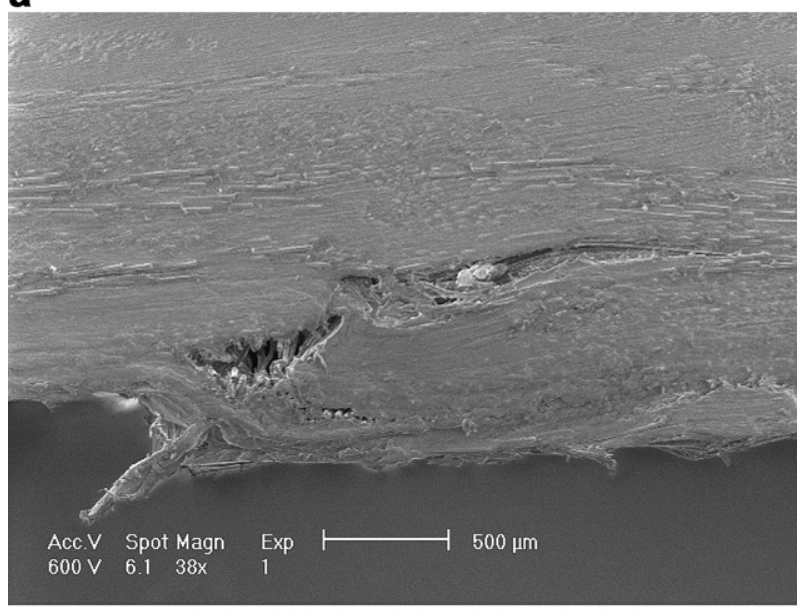

b

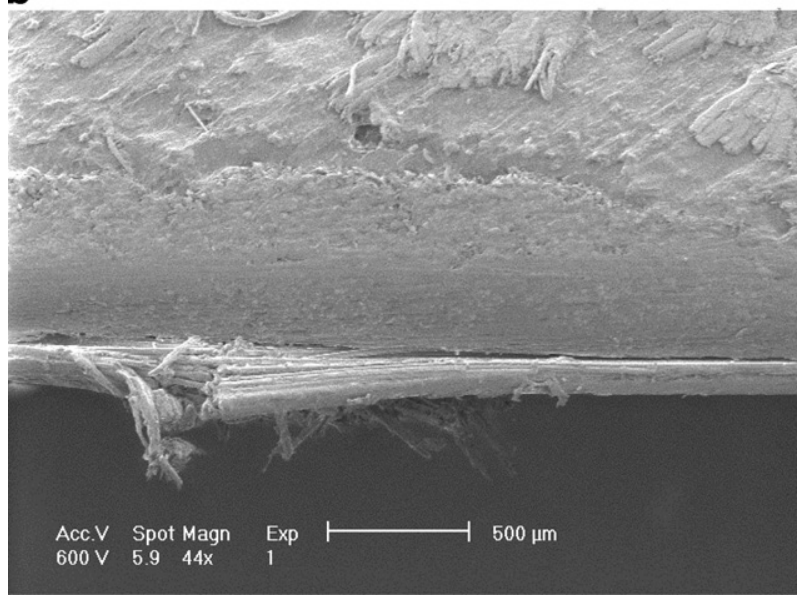

Fig. 6. Failure mechanisms for: (a) laminated composites, (b) hybrid laminated composites.

In both laminates the delaminations in the interface layers have an important role on the failure process. Ferreira et al. [34] also verified the significance of the interface shear stresses, for adhesive joints with natural fibres reinforced interface layers.

The results of the fatigue tests are plotted in Fig. 7a in terms of the stress range versus the number of cycles to failure. The failure criterion was defined when the stiffness
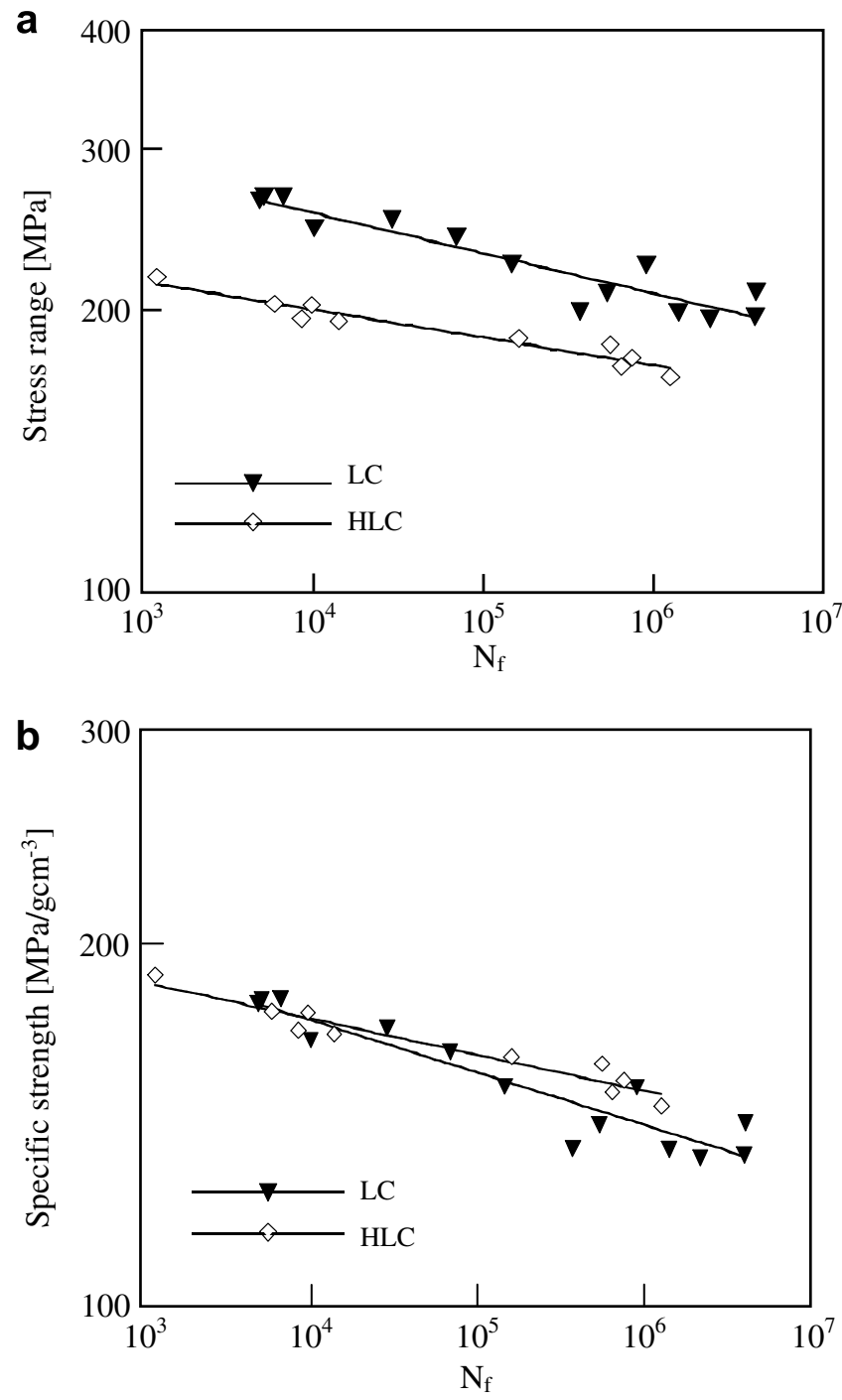

Fig. 7. $S-N$ curves for laminated and hybrid laminated composites.

reaches $80 \%$ of the initial value. Fig. 7 a shows that the fatigue strength of the laminated composites is $1.2-1.4$ times higher than hybrid laminated composites. This effect was caused by the change of the failure mechanisms and is a direct consequence of the observed decrease of the static strength. 
Fig. $7 \mathrm{~b}$ shows the same results in terms of the specific fatigue strength (stress range/specific mass) against the number of cycles to failure. Inspite of its lower fatigue strength HLC composite presents higher specific fatigue strength than the LC laminates. These results and the economical and ecological benefits associated with the hybrid laminates make them promising materials for structural applications where bending loadings are predominant.

Fig. 8 shows the fatigue damage modes for laminated and hybrid laminated composites. Two main failure modes

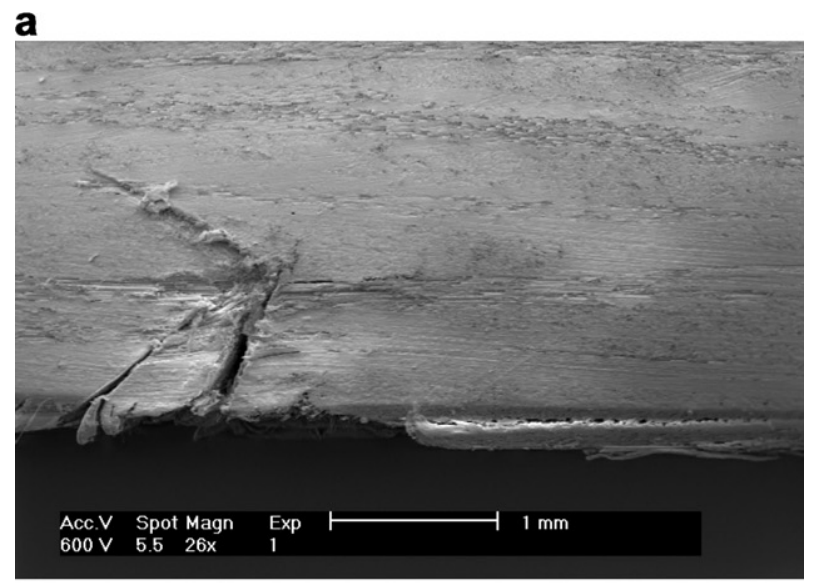

b

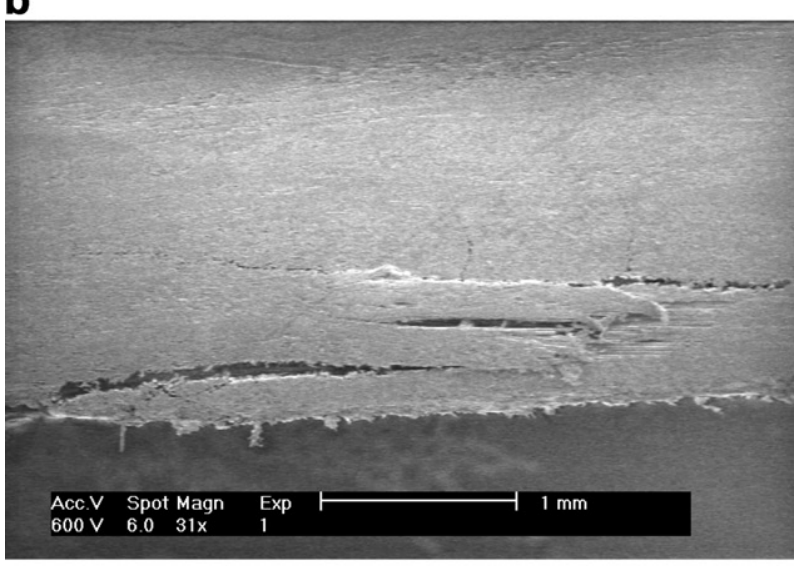

c

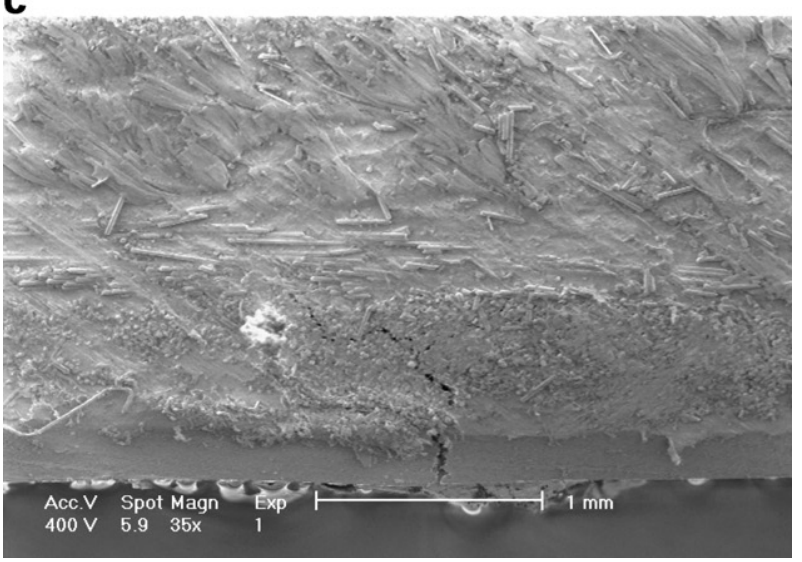

Fig. 8. Failure aspect for laminated composites (a) stress of $266 \mathrm{MPa}$, (b) stress of $196 \mathrm{MPa}$, and hybrid laminated composites, (c) stress of $170 \mathrm{MPa}$.

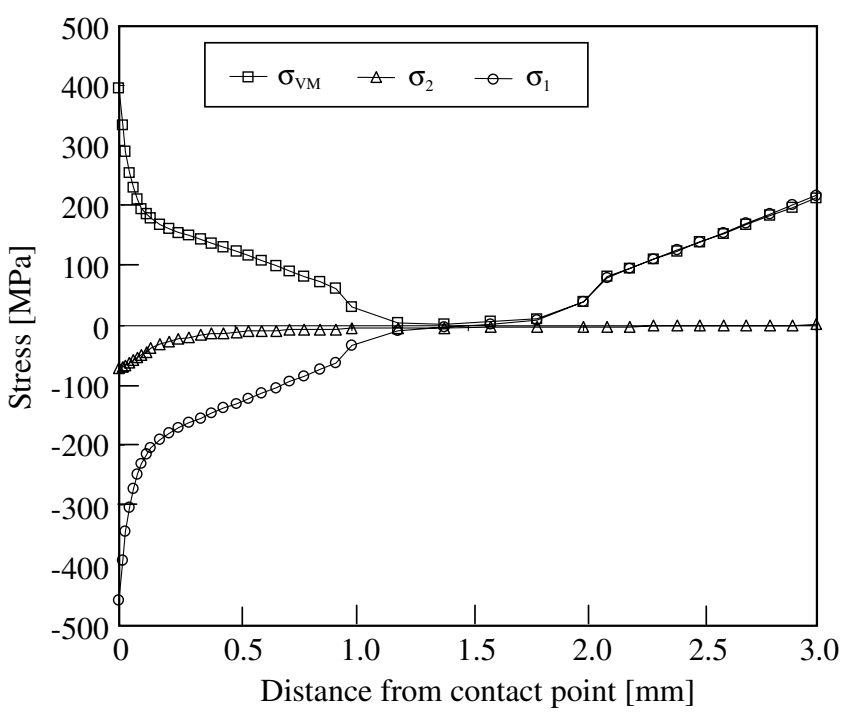

Fig. 9. Stresses along the thickness.
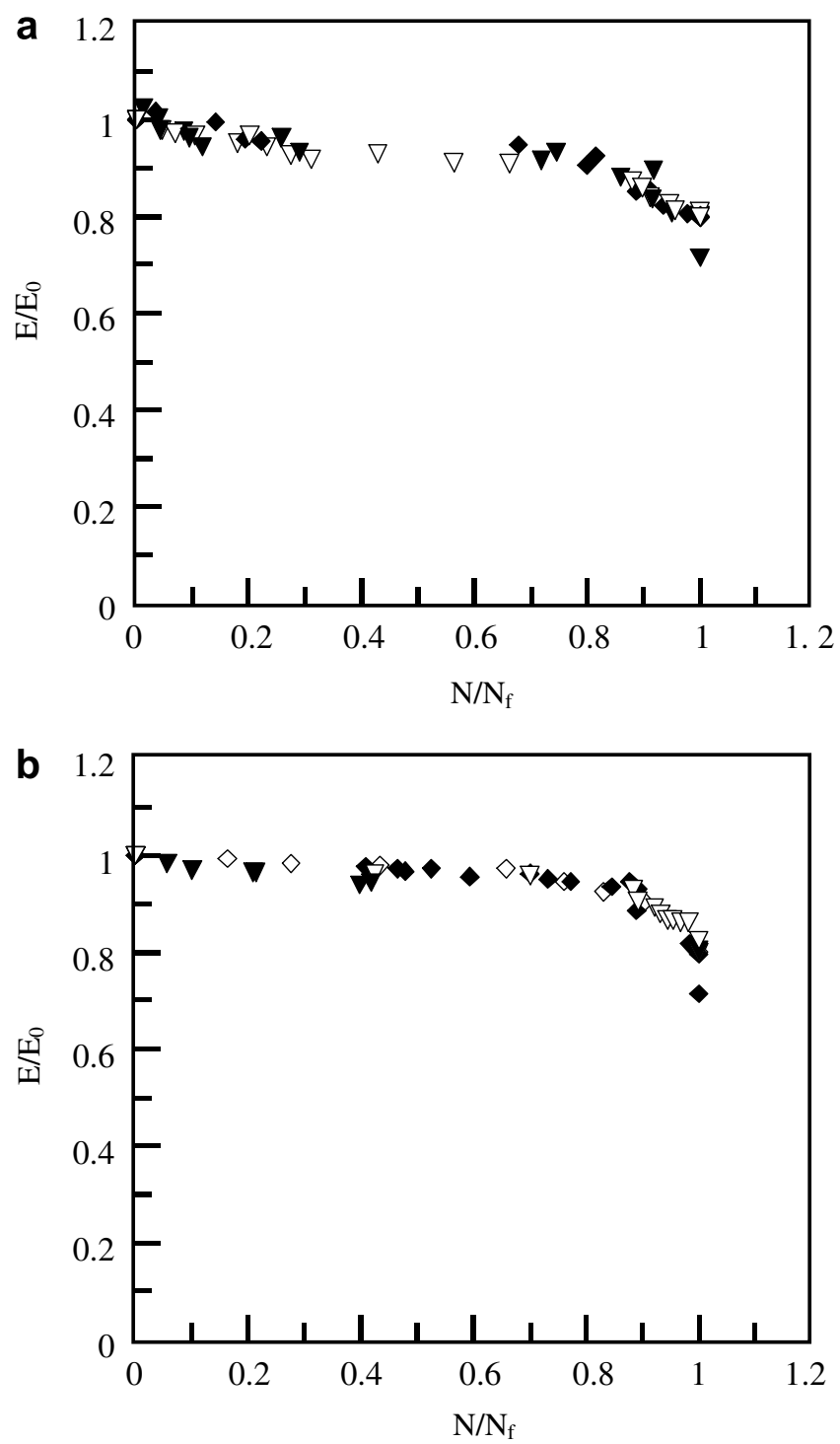

Fig. 10. $E / E_{0}$ against the normalised number of cycles $N / N_{\mathrm{f}}$ : (a) laminated composites, (b) hybrid laminated composites. 
can be identified for laminated composites. For relatively high stress levels (Fig. 8a) the failure is associated with fibres rupture produced by compressive stresses and the scatter of results is relatively small. On the other hand,

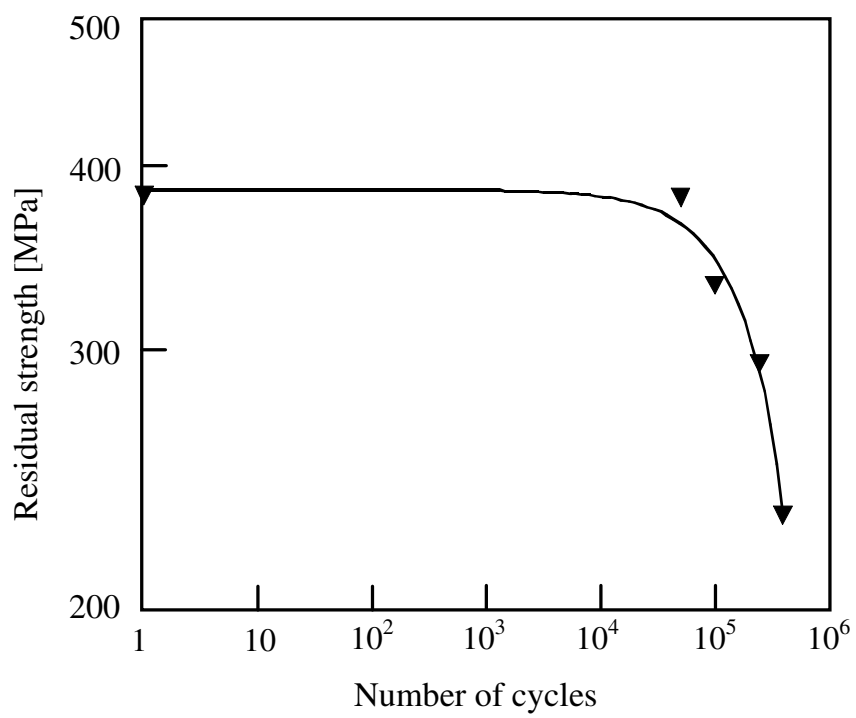

Fig. 11. Residual strength versus number of fatigue cycles for laminated composites. for lower stress levels and longer lives the failure is mainly due to delamination, Fig. 8b, and fatigue life has a higher scatter level. For hybrid laminated composites the microscopy analysis (Fig. 8c) indicates that the main failure mode (fibres failure by compressive stresses), both for high and low stress levels are similar to that observed for static tests. However, for low stresses the rupture of polypropylene and natural fibres inside of the hybrid laminated composite was also observed.

The microscopy analysis reveals that the faster failure mechanism was always broken in longitudinal glass fibres in the compression side of the specimen as a consequence of the low compressive strength of the fibres. To improve the understanding of this process, a finite element stress analysis was performed on the compressive and interface regions of the hybrid laminated composite specimens.

Fig. 9 presents the longitudinal stresses, $\sigma_{1}$, the thickness direction stresses, $\sigma_{2}$, and Von Mises equivalent stresses, $\sigma_{\mathrm{VM}}$, versus distance to point $\mathrm{A}$, which is measured along the thickness. Point $\mathrm{A}$ is the contact of the specimen with the central pin. It can be seen that $\sigma_{2}$ stresses are different from zero near contact point and $\sigma_{1}$ stress has a linear variation that is typical of flexure distributions. However, higher values are obtained near point A resulting from contact. Between 1 and $2 \mathrm{~mm}$, corresponding to the layer of PP

C
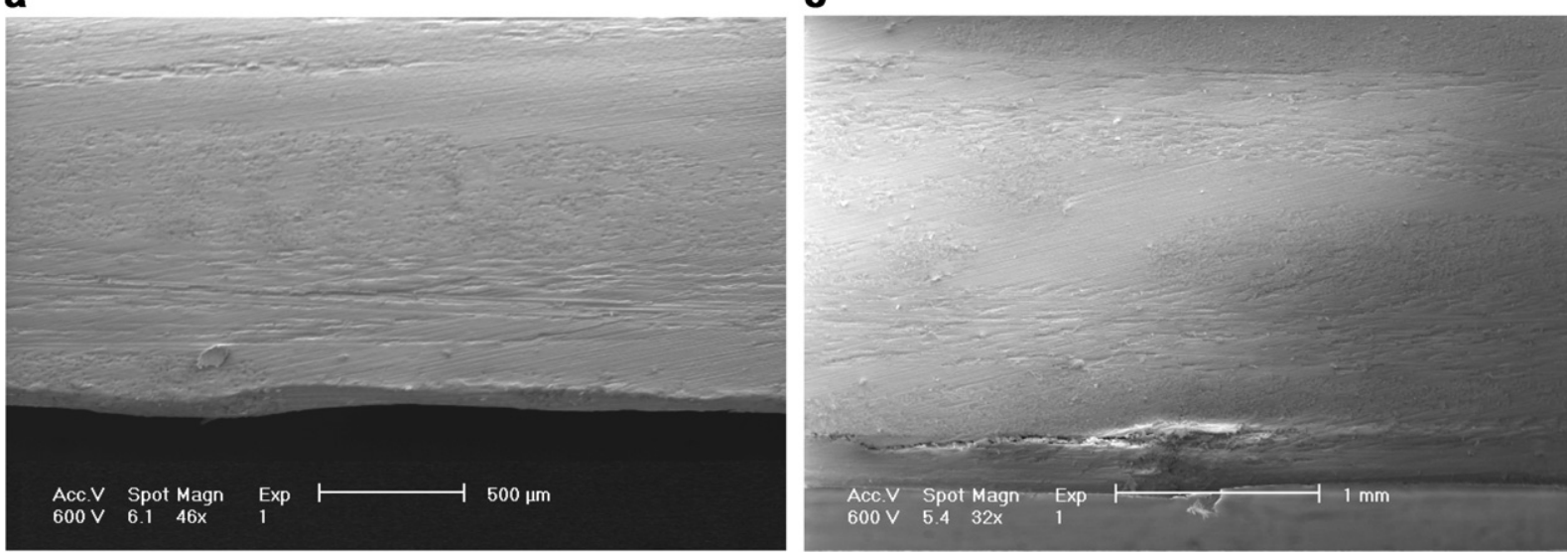

b

d
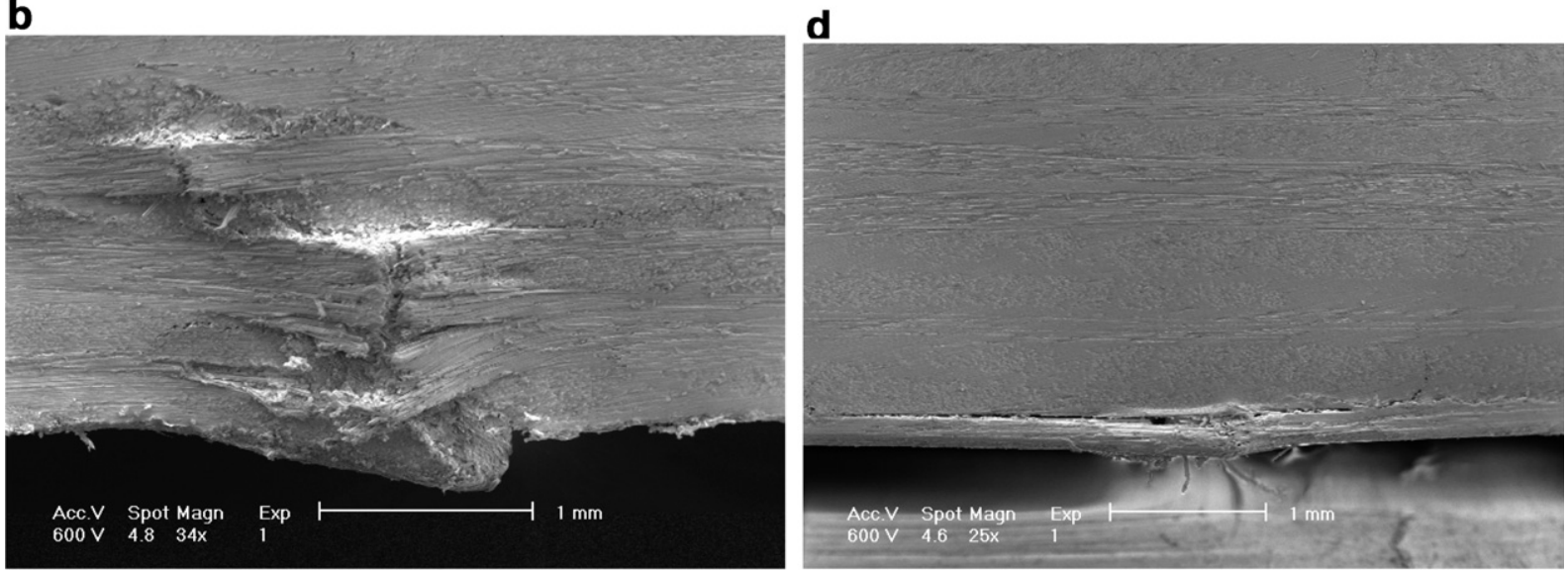

Fig. 12. Failure damage for (a) $5 \times 10^{4}$ cycles, (b) $10^{5}$ cycles, (c) $2.5 \times 10^{5}$ cycles, (d) $4 \times 10^{5}$ cycles. 
with natural fibres, stresses are lower, which is explained by the lower elastic stiffness of this material. Therefore, its deformation is easier and it supports lower forces. The high compressive stress concentration in the pin load contact region associated with the low compressive strength of the fibres promotes the compressive broken of longitudinal fibre in this region as the early failure mechanism.

The variation in stiffness modulus during the tests was also measured experimentally. The stiffness was calculated by a linear regression of the stress-strain data. This fatigue damage parameter was plotted in Fig. 10 in terms of $E / E_{0}$ versus $N / N_{\mathrm{f}}$, where $E$ is the current stiffness modulus, $E_{0}$ is the initial stiffness modulus, $N$ is the current number of loading cycles and $N_{\mathrm{f}}$ is the number of cycles to failure. These data show that the different laminates studied present distinct behaviour. The laminated composites (Fig. 10a) present a significant drop of $E / E_{0}(4-6 \%)$ at the early stage of the fatigue life $(5 \%)$; followed by a second stage, where only a slow decrease was observed until near failure, where a sudden drop of $E / E_{0}$ occurs. This behaviour is controlled by the damage occurring in the composite, being each stage associated with a defined failure mode, similarly to the observed by the authors in tensile tests [30] and by others authors [35-37]. For the hybrid laminated composites the first stage was not observed. The stiffness decreases slowly up to the last $15-20 \%$ of fatigue life, where it presents a sudden drop until failure. The absence of the first stiffness drop stage can be a consequence of the lower stress levels of the tests being not enough to produce significant creep or matrix failure, which are two important mechanisms of the early fatigue damage.

The growing of fatigue damage was also monitored using the residual strength of the laminated composites. Fig. 11 shows the residual strength (MPa) versus number of fatigue cycles. A stress range of $215 \mathrm{MPa}$ was considered in this study, for which a fatigue life of $5 \times$ $10^{5}$ cycles was expected. Measurements of residual stress were made at $5 \times 10^{4}, 10^{5}, 2.5 \times 10^{5}$, and $4 \times 10^{5}$ fatigue cycles. Damage evolution was also analysed by microscopy (Fig. 12).

It can be observed in Fig. 11 that up to $5 \times 10^{4}$, cycles the residual strength is similar to that observed in static tests. This behaviour indicates that no significant damage occurred in laminates, as shows Fig. 12. Later, residual strength decreased up to about $40 \%$ of static resistance for a life of $4 \times 10^{5}$ cycles. In the SEM images of Fig. $12 \mathrm{~b}-\mathrm{d}$, it is possible to observe that around $10^{5}$ loading cycles, the rupture occurs by compression in some fibres, producing delamination and posterior propagation.

\section{Conclusions}

- Laminate composites (LC) present an ultimate strength about 4\% higher than the hybrid laminated composites (HLC) associated to changes in failure mechanisms, while the stiffness' modulus was also about 3.8\% higher. Fatigue strength of hybrid laminated composites is also about $20 \%$ lower than the laminated composites as consequence of the change of the failure mechanisms and of the different static strengths. However, specific static stiffness and strength of HLC are about 22\% higher than those obtained for LC material. The specific fatigue strength of HLC is also higher compared with LC specimens.

- For laminated composites the main damage mechanism is the fracture of the fibres in compression. Small delaminations appeared around of the broken fibres. For hybrid laminated composites the first fibre ruptures appeared also in the compression region followed by a long delamination between the core and the skin. Finally, this delamination lead to the tensile rupture of the fibres. Failure mechanisms in hybrid laminated composites are strongly influenced by the high gradients of shear and normal stresses near the interface between the core and the skin and also by the high magnification of compressive stresses near the contact of specimen with central pin.

\section{References}

[1] Moon Chang-Kwon. The effect of interfacial microstructure on the interfacial strength of glass fiber/polypropylene resin composites. J Appl Polym Sci 1994;54:73-82.

[2] Joseph PV, Joseph K, Thomas S. Effect of processing variables on the mechanical properties of sisal-fiber-reinforced polypropylene composites. Compos Sci Technol 1999;59:1625-40.

[3] Saheb DN, Jog JP. Natural fiber polymer composites: a review. Adv Polym Technol 1999;18(4):351-63.

[4] Folkes MJ. Short fiber reinforced thermoplastic composites. New York: John Wiley and Sons; 1982.

[5] Bledzki AK, Gassan J. Natural fiber reinforced plastics. In: Handbook of engineering polymeric materials. New York: Marcel Dekker, Inc.; 1997. p. 787-810.

[6] Jayaraman K. Manufacturing sisal-polypropylene composites with minimum fibre degradation. Compos Sci Technol 2003;63:367-74.

[7] Opportunities for natural fibers in plastic composites. Little Falls, NJ, USA: Kline \& Company, Inc.; 2000.

[8] Mapleston P. Natural-fibre composites rev-up role in interior panels. Mod Plast Int 1997(May):39-40.

[9] Larbig H, Scherzer H, Dahlke B, Poltrock R. Natural fibre reinforced foams based on renewable resources for automotive interior applications. J Cell Plast 1998;34:361-79.

[10] Leao A, Rowell R, Tavares N. Applications of natural fibres in automotive industry in Brazil-thermoforming process. In: 4th international conference on frontiers of polymers and advanced materials conference proceedings. Cairo, Egypt: Plenum Press; 1997. p. $755-60$.

[11] Bledzki AK, Reihmane S, Gassan J. Properties and modification methods for vegetable fibres for natural fibre composites. J Appl Polym Sci 1996;59:1329-36.

[12] Bledzki AK, Zhang W, Chate A. Natural fibre reinforced polyurethane microfoams. Compos Sci Technol 2001;61:2405-11.

[13] Van de Velde K, Kiekens P. Thermoplastic pultrusion of natural fibre reinforced composites. Compos Struc 2001;54:355-60.

[14] Wambua P, Ivens J, Verpoest I. Natural fibres: can they replace glass in fibre reinforced plastics? Compos Sci Technol 2003;63:1259-64.

[15] Dhakal HN, Zhang ZY, Richardson MOW. Effect of water absorption on the mechanical properties of hemp fibre reinforced unsaturated polyester composites. Compos Sci Technol 2006. doi:10.1016/ j.compscitech.2006.06.019. 
[16] Mills NJ. Plastic, Microstructure and engineering applications. Edward Arnold; 1993.

[17] Van Den Oever M, Peijs T. Continuous-glass-fibre-reinforced polypropylene composites II. Influence of maleic-anhydride modified polypropylene on fatigue behaviour. Composites Part A 1998;29A: 227-39.

[18] Joshep K, Thomas S. Effect of chemical treatment on the tensile properties of short sisal fibre-reinforced polyethylene composites. Polymer 1996;37:5139-49.

[19] Herrera-Franco P, Aguilar-Vega M. Effect of fibre treatment on the mechanical properties of LDPE-henequen cellulosic fibre composites. J Appl Polym Sci 1997;10:197-207.

[20] Hepworth DG, Hobson RN, Bruce DM, Farrent JW. The use of unretted hemp fibre in composite manufacture. Composites Part A 2000;31:1279-83.

[21] Mohanty AK, Misra M, Drzal LT. Surface modifications of natural fibers and performance of the resulting biocomposites: an overview. Compos Interface 2001;8(5):313-43.

[22] Mohanty AK, Drzal LT, Misra M. Engineered natural fiber reinforced polypropylene composites: influence of surface modifications and novel powder impregnation processing. J Adhes Sci Technol 2002;16(8):999-1015.

[23] Mwaikambo L, Ansell M. Chemical modification of hemp, sisal, jute and kapok fibres by alkalisation. J Appl Polym Sci 2002;84(12): 2222-34.

[24] Mishra S, Naik JB, Patil YP. The compatibilising effect of maleic anhydride on swelling and mechanical properties of plant-fiberreinforced Novolac composites. Compos Sci Technol 2000;60: $1729-35$.

[25] Mwaikambo LY, Ansell MP. Hemp fibre reinforced cashew nut shell liquid composites. Compos Sci Technol 2003;63:1297-305.

[26] Fernando G, Dickson RF, Adam T, Reiter H, Harris B. Fatigue behaviour of hybrid composites: part I. Carbon-Kevlar hybrids. J Mater Sci 1988;23:3732-43.
[27] Dickson RF, Fernando G, Adam T, Reiter H, Harris B. Fatigue behaviour of hybrid composites: part II. Carbon-glass hybrids. J Mater Sci 1989;24:227-33.

[28] Maron G, Harel H, Neumann S, Friedrich K, Schulte K, Wagner HD. Fatigue behaviour and rate dependent properties of aramid fibre/carbon fibre hybrid composite. Composites 1989;20:53744.

[29] Shan Y, Liao K. Environmental fatigue behavior and life prediction of unidirectional glass-carbon epoxy hybrid composites. Int J Fatigue 2002;24:847-59.

[30] Ferreira JAM, Costa JDM, Reis PNB. Static and fatigue behaviour of glass-fibre-reinforced polypropylene composites. Theor Appl Fract Mech 1999;31:67-74.

[31] Ferreira JAM, Costa JDM, Reis PNB, Richardson MOW. Analysis of fatigue and damage in glass-fibre-reinforced polypropylene composite materials. Compos Sci Technol 1999;59:1461-7.

[32] American Society for Testing and Materials. Standard test method for apparent interlaminar shear strength of parallel fiber composites by short-beam method. Annual book of ASTM standards, section 15, 15.03, D 2344-84;1999.

[33] MARC user information. Palo Alto: Marc Analysis Research Corp; 2003

[34] Ferreira JAM, Silva H, Costa JDM, Richardson MOW. Stress analysis of lap joints involving natural fibre reinforced interface layers. Composites Part B 2005;36:1-7.

[35] Reifsnider KL, Highsmith AL. The relationship of stiffness changes in composite laminates to fracture-related damage mechanisms. In: Sih GC, Tamuzs VP, editors. Fract Compos Mater. The Hague: Martinus Nijhoff Publishers; 1982. p. 279-90.

[36] Steif PS. Stiffness reduction due to fiber breakage. J Compos Mater 1984;17:153-72.

[37] Ferreira JAM, Costa JDM, Richardson MOW. Effect of notch and test conditions on the fatigue of a glass-fibre-reinforced polypropylene composite. Compos Sci Technol 1997;57:1243-8. 